Research Article

\title{
Differences in Adrenal Size as they Relate to Pheochromo- cytomas
}

Daniela Guevara ${ }^{1}$, Aryan Meknat ${ }^{1}$, Aida Taye Bellistri ${ }^{2}$, Hyunsuk Suh ${ }^{3}$, Alice C Levine ${ }^{4}$, William Inabnet III ${ }^{5}$ and Gustavo Fernández-Ranvier ${ }^{1^{*}}$

${ }^{1}$ Division of Metabolic, Endocrine and Minimally Invasive Surgery, Department of Surgery, Mount Sinai Hospital, Icahn School of Medicine at Mount Sinai, USA

${ }^{2}$ Division of Endocrine and General Surgery, Mount Sinai West \& St. Luke's Hospital, Icahn School of Medicine at Mount Sinai, USA

${ }^{3}$ Division of General Surgery, Department of Surgery, Mount Sinai Hospital, Icahn School of Medicine at Mount Sinai, USA

${ }^{4}$ Division of Endocrinology, Metabolism and Bone Diseases, Icahn School of Medicine at Mount Sinai, USA

${ }^{5}$ Department of Surgery, University of Kentucky, USA

\begin{abstract}
Introduction: Pheochromocytomas can present with a wide variety of clinical features. Tumor size of pheochromocytomas can often be as variable as its symptomology. The purpose of this investigation is to evaluate the differences in the clinical features, the biochemical values, and their relationship to the tumor size.

Materials and methods: We retrospectively reviewed records of 102 patients diagnosed with a pheochromocytoma, treated at our institution between 1999 and 2014. Clinical characteristics and laboratory values were obtained after reviewing the electronic medical records. For data analysis and comparison, the patients were stratified into three groups according to tumor size: group $A(<4 \mathrm{~cm}, \mathrm{n}=26)$; group $B(4-8 \mathrm{~cm}, \mathrm{n}=45)$ and group $C(>8 \mathrm{~cm}, \mathrm{n}=14)$.

Results: Eighty-five patients were included in the study. In group-A 19 were female and 7 were male with an average age of $49.9 \pm 17$ (19-69). In group-B, there were 32 males and 13 females with an average age of $49.4 \pm 13.7$ (25-77). In group-C, there were 8 males and 6 females with an average age of $54.8 \pm 17.3$ (31-84). The average tumor size was 2.5 $\mathrm{cm}(1-3.5)$ in group-A, $5 \mathrm{~cm}(4-7.5)$ in group-B, and $9.82 \mathrm{~cm}(8.5-16)$ in group-C. The preoperative average hormonal level (plasma normetanephrines/metanephrines nmol/l) was 5.53/4.78 for group-A, 8.34/4.11 for group-B and 27.37/8.42 for group $C$. There was a statistically significant difference when comparing normetanephrine/metanephrine levels, relative to tumor size. Specifically, when comparing group A to group C, group B to C, but not group A to B. When considering hyperadrenergic symptoms (e.g. hypertension, headaches, palpitation and sweating), relative to size, there was only a statistically significant difference in the presence of hypertension-but only when there was a larger discrepancy in size (i.e. $<4$ vs. $>8 \mathrm{~cm}$ ).

Conclusion: This investigation demonstrated that tumor size could have an influence on the degree of plasma noremetanephrine/metanephrine secretion. On the other hand, we found that tumor size has no impact on the presence of hyperadrenergic symptoms, except for hypertension.
\end{abstract}

Keywords

Pheochromocytoma, Tumor size, Metanephrine, Normetanephrine

\section{Introduction}

Pheochromocytomas (PCC) are rare neuroendocrine tumors originating from the adrenal medulla and/or extra-adrenal para-ganglionic tissues. These chromaffin tumors can present as functional tumors with hyper-adrenergic symptoms or as incidentally encountered tumors on a radiological scan (non-secretory, non-functional tumors) [1,2]. Incidence among the general population is about 0.8 per 100.000 persons per year, and it is estimated to be $0.2-0.6 \%$ in the hypertensive population [1]. The hyper-adrenergic syndrome asso-
*Corresponding author: Gustavo Fernández-Ranvier, Division of Metabolic, Endocrine and Minimally Invasive Surgery, Department of Surgery, Mount Sinai Hospital, Icahn School of Medicine at Mount Sinai, 5 East 98th Street 15th floor New York, NY 10029, USA, Tel: 212-241-5339

Accepted: February 15, 2020

Published online: February 17, 2020

Citation: Guevara D, Meknat A, Bellistri AT, Suh H, Levine AC, et al. (2020) Differences in Adrenal Size as they Relate to Pheochromocytomas. J Surgical Endocrinol 2(1):16-20 
Citation: Guevara D, Meknat A, Bellistri AT, Suh H, Levine AC, et al. (2020) Differences in Adrenal Size as they Relate to Pheochromocytomas. J Surgical Endocrinol 2(1):16-20

ciated with these tumors occurs as a result of catecholamine excess - manifesting classically as paroxysmal hypertension, episodic tachycardia, sweating, headaches, and/or dizziness. PCC can vary in their presentation, from asymptomatic with episodic symptoms to continuous symptoms with intermittent adrenergic crises [3]. This all depends on the secretion profile of the tumor; the rate, the amount, and/or the predominant catecholamine (e.g. epinephrine versus norepinephrine) secreted [3-6]. Atypical symptoms that should not be overlooked during a diagnostic work-up of an adrenal medullary tumor include: Chest pain, headaches, diaphoresis, and panic attacks. The majority of pheochromocytomas are diagnosed after work-up of signs and symptoms of catecholamine excess, but there is a proportion that is encountered incidentally on radiological scans done for other reasons. These adrenal lesions are termed "incidentalomas" and it is critical to rule out a PCC to prevent hemodynamic crisis with appropriate medical management before any surgery should be undertaken [7]. Diagnosis is confirmed by measuring plasma free metanephrines, which offers a diagnostic sensitivity of more than $97 \%$. Once diagnosed, localization is most commonly done with a CT scan or MRI. In cases where these two radiological exams are unable to locate the adrenal medullary tumor, an MIBG scan (i.e. metaiodobenzylguanidine scan) is done $[2,3,8]$.

Once a functional pheochromocytoma has been identified, determination of whether or not it is malignant is undertaken. The old school of thought was that adrenal lesions greater than or equal to $6 \mathrm{~cm}$ were likely malignant, therefore an open adrenalectomy would be safer than a laparoscopic procedure $[9,10]$. Now, unless there are clinical and/ or radiological signs of malignancy, size is no longer a major determinant of the feasibility of a laparoscopic adrenalectomy. Nor is size used to correlate with probability with underlying malignancy [9-12]. Ominous signs of malignancy, on CT scan, include: Non-homogenous tissue, peripheral enhancement with contrast, central areas of necrosis or calcification, growth into surrounding tissues, $<50 \%$ washout of contrast, and/or $>10-20$ Hounsfield units [11-13]. These tumors typically range in size between 1 to $15 \mathrm{~cm}$, potentially even larger, and may present with varying degrees of catecholamine excess and hyper-adrenergic symptoms [13]. The aim of this retrospective study is to evaluate differences in the biochemical values, degree of clinical symptoms, and peri-operative hemodynamic status relative to chromaffin tumor size.

\section{Material and Methods}

Outcomes were analyzed from a prospectively maintained, IRB-approved database. All research was conducted after the approval from the institutional review board was obtained. We retrospectively analyzed the charts of 102 patients who had an adrenalectomy done for a diagnosed PCC, between 1999 and 2014. The tumors were diagnosed by correlating an elevation of plasma metanephrines and normetanephrines with the presence of an adrenal mass. The diagnosis was confirmed on pathological analysis. Demographics such as age, gender, weight, body mass index (BMI), and co-morbidities were recorded. Plasma metanephrine/normetanephrine levels, the presence or absence of hyper-adrenergic symptoms, tumor size and location were also documented. Documentation of blood pressure was done during the peri-operative period as well. Eighty-five of the 102 patients were included in the study, as patients with bilateral pheochromocytomas or extra-adrenal pheochromocytomas were excluded from this investigation. For data analysis and comparison, the patients were stratified into 3 groups according to tumor size. Group A $(n=26)$ had a tumor size of $<4 \mathrm{~cm}$ in its greatest diameter; Group B $(n=45)$ had a tumor size $\geq 4$ but $<8 \mathrm{~cm}$ in its greatest diameter; Group $C(n=14)$ had pheochromocytomas $\geq 8 \mathrm{~cm}$ in its greatest diameter.

Hypertension was defined as a systolic and/or diastolic blood pressure (SBP, DBP) equal to or greater than 140 and $90 \mathrm{mmHg}$, respectively; or else as the need to use two or more anti-hypertensive medications to maintain blood pressure within normal range. Diabetes was diagnosed according to the American Diabetes Association (ADA) guidelines. Diabetes was diagnosed if the $\mathrm{HbA} 1 \mathrm{C}$ was greater than or equal to $6.5 \%$, if fasting blood glucose was greater than or equal to $126 \mathrm{mg} / \mathrm{dl}$, and/or if the oral glucose tolerance test (OGTT) was greater than or equal to $200 \mathrm{mg} /$ dl. At our facility laparoscopic surgery is the standard operative approach for the resection of pheochromocytomas. In our practice, tumors larger than $9 \mathrm{~cm}$ can still be safely removed via this approach. An open approach was only utilized when malignancy was suspected.

We assessed for significant differences in mean outcomes measured between the two groups by using paired t-tests to generate a two-tailed $p$-value. Statistical significance was defined as a p-value less than 0.05. Calculations were performed with LaTeX.

\section{Results}

All 85 patients were found to have functional pheochromocytomas, based on their biochemical profiles. There were 19 females and 7 males with an average age of $49.9 \pm 17$ (1969 ) in Group A. There were 13 females and 32 males with an average age of $49.4 \pm 13.7$ (25-77) in Group B. There were 6 females and 8 males with an average age of $54.8 \pm 17.3$ (31-84) in Group C. Mean tumor sizes were $2.5 \pm 0.7$ (1-3.5), $5.6 \pm 1.3(4-8)$, and $9.8 \pm 2.4$ (8.5-16) for Group A, B, and C, respectively. Laparoscopic adrenalectomies were performed for $23(84.5 \%), 41(91.1 \%)$, and $9(64.3 \%)$ of the patients in Group $A, B$, and $C$, respectively. Only 5 patients underwent open adrenalectomies, 2 (7.7\%) in Group A, 1 (2.2\%) in Group $B$, and $2(14.3 \%)$ in Group C. Conversion from a laparoscopic to an open procedure was necessary in $1(3.8 \%)$ patient from Group A, 3 (6.7\%) in Group B, and 3 (21.4\%) in Group C. The details of the above findings are listed in Table 1.

Pre-operative mean heart rate (bpm) and blood pressure $(\mathrm{mmHg})$ were recorded and analyzed, as illustrated in Table 2. The mean heart rate and blood pressure for patients in Group A was $81 \pm 16.2$ and 136.5/81.8 \pm 15/17.2, respectively. Amongst Group B patients, the mean heart rate and blood pressure was $81.3 \pm 14.5$ and $138 / 82.4 \pm$ $31.4 / 16.4$, respectively. Group C patients had a mean heart rate and blood pressure of $89.7 \pm 21.9$ and $133.1 / 74.3 \pm$ 
Citation: Guevara D, Meknat A, Bellistri AT, Suh H, Levine AC, et al. (2020) Differences in Adrenal Size as they Relate to Pheochromocytomas. J Surgical Endocrinol 2(1):16-20

Table 1: Patient and tumor characteristics.

\begin{tabular}{|c|c|c|c|}
\hline & $\begin{array}{l}\text { Group A } \\
(n=26)[<4 \mathrm{~cm}]\end{array}$ & $\begin{array}{l}\text { Group B } \\
(n=45)[4-8 \mathrm{~cm}]\end{array}$ & $\begin{array}{l}\text { Group C } \\
(n=14)[>8 \mathrm{~cm}]\end{array}$ \\
\hline \multicolumn{4}{|l|}{ Patient demographics } \\
\hline $\begin{array}{l}\text { Female } \\
\text { Male } \\
\text { Age } \\
\text { Weight (lbs.) } \\
\text { BMI (pre Op.) }\end{array}$ & $\begin{array}{l}19(73.1 \%) \\
7(23.9 \%) \\
49.9 \pm(17)[19-69] \\
158.8 \pm(37.1) \\
27.3 \pm(7.2)\end{array}$ & $\begin{array}{l}32(71.1 \%) \\
13(28.9 \%) \\
49.4 \pm(13.7)[25-77] \\
173.2 \pm(33.4) \\
28.5 \pm(6.3)\end{array}$ & $\begin{array}{l}8(57.2 \%) \\
6(42.8 \%) \\
54.8 \pm(17.3)[31-84] \\
170.6 \pm(49.9) \\
28.3 \pm(8.3)\end{array}$ \\
\hline \multicolumn{4}{|l|}{ Tumor characteristics } \\
\hline $\begin{array}{l}\text { Tumor size (cm) } \\
\text { Tumor weight (gr.) } \\
\text { Left Side } \\
\text { Right Side }\end{array}$ & $\begin{array}{l}2.5 \pm(0.7)[1-3.5] \\
27.3 \pm(23.2) \\
14(53.8 \%) \\
12(46.1 \%)\end{array}$ & $\begin{array}{l}5.6 \pm(1.3)[4-8] \\
56.9 \pm(41.8) \\
23(51.1 \%) \\
22(48.9 \%)\end{array}$ & $\begin{array}{l}9.8 \pm(2.4)[8.5-16] \\
217.7 \pm(125.4) \\
6(42.8 \%) \\
8(57.2 \%)\end{array}$ \\
\hline \multicolumn{4}{|c|}{ Initial operative approach } \\
\hline $\begin{array}{l}\text { Laparoscopic } \\
\text { Open } \\
\text { Converted Operation }\end{array}$ & $\begin{array}{l}23(84.5 \%) \\
2(7.7 \%) \\
1(3.8 \%)\end{array}$ & $\begin{array}{l}41(91.1 \%) \\
1(2.2 \%) \\
3(6.7 \%)\end{array}$ & $\begin{array}{l}9(64.3 \%) \\
2(14.3 \%) \\
3(21.4 \%)\end{array}$ \\
\hline
\end{tabular}

BMI: Body Mass Index; SBP: Systolic Blood Pressure; DBP: Diastolic Blood Pressure; bpm: Beats Per Minute. Values expressed as means \pm SD.

Table 2: Pre-operative vitals.

\begin{tabular}{|l|l|l|l|}
\hline & $\begin{array}{l}\text { Group A } \\
(\mathbf{n}=\mathbf{2 6})[<\mathbf{4} \mathbf{~ c m}]\end{array}$ & $\begin{array}{l}\text { Group B } \\
(\mathbf{n = 4 5})[\mathbf{4 - 8} \mathbf{~ c m}]\end{array}$ & $\begin{array}{l}\text { Group C } \\
(\mathbf{n}=\mathbf{1 4})[>\mathbf{8 c m}]\end{array}$ \\
\hline Pulse $(\mathrm{bpm})$ & $81 \pm(16.2)$ & $81.3 \pm(14.5)$ & $89.7 \pm(21.9)$ \\
\hline SBP $(\mathrm{mmHg})$ & $136.5 \pm(15)$ & $138 \pm(31.4)$ & $133.1 \pm(22.3)$ \\
\hline DBP $(\mathrm{mmHg})$ & $81.8 \pm(7.2)$ & $82.4 \pm(16.4)$ & $74.3 \pm(10)$ \\
\hline
\end{tabular}

SBP: Systolic Blood Pressure; DBP: Diastolic Blood Pressure; bpm: Beats Per Minute. Values expressed as means \pm SD.

Table 3: Biochemical characteristics.

\begin{tabular}{|l|l|l|l|}
\hline Biochemical diagnosis & $\begin{array}{l}\text { Group A } \\
(\mathbf{n = 2 6 )}[<\mathbf{4} \mathbf{c m}]\end{array}$ & $\begin{array}{l}\text { Group B } \\
(\mathbf{n = 3 9 )}[\mathbf{4 - 8} \mathbf{c m}]\end{array}$ & $\begin{array}{l}\text { Group C } \\
(\mathbf{n}=\mathbf{1 4})[>\mathbf{8} \mathbf{c m}]\end{array}$ \\
\hline Normetanephrines (nmol/l) & $5.5 \pm(10.2)$ & $9 \pm(12.5)$ & $27.4 \pm(16.6)$ \\
\hline Metanephrines (nmol/l) & $1.3 \pm(2.5)$ & $4.8 \pm(7.9)$ & $8.4 \pm(8.1)$ \\
\hline
\end{tabular}

Values expressed as means \pm SD. Normal values: Normetanephrines 0.00-0.89 nmol/L; Metanephrines: 0.00-0.49 nmol/L.

Table 4: Clinical symptoms and associated co-morbidities relative to tumor size.

\begin{tabular}{|l|l|l|l|}
\hline Clinical manifestations & $\begin{array}{l}\text { Group A } \\
\text { (n= 26) [< } \mathbf{~ c m ] ~}\end{array}$ & $\begin{array}{l}\text { Group B } \\
\text { (n= 39) [4-8 cm] }\end{array}$ & $\begin{array}{l}\text { Group C } \\
\text { (n= 14) [> 8 cm] }\end{array}$ \\
\hline Headache & $3(11.5 \%)$ & $12(26.7 \%)$ & $3(21.4 \%)$ \\
\hline Palpitation & $6(23 \%)$ & $3(6.7 \%)$ & $4(28.6 \%)$ \\
\hline Sweating & $4(15.4 \%)$ & $1(2.2 \%)$ & $2(14.3 \%)$ \\
\hline Dizziness & 0 & $3(6.7 \%)$ & $1(7.1 \%)$ \\
\hline Nausea & 0 & $1(2.2 \%)$ & $1(7.1 \%)$ \\
\hline Blurred of vision & $1(3.8 \%)$ & $32(71.1 \%)$ & 0 \\
\hline Hypertension & $15(57.7 \%)$ & $2(4.4 \%)$ & $12(85.7 \%)$ \\
\hline Congestive Heart Failure & 0 & $1(2.2 \%)$ & 0 \\
\hline NIDDM & $2(7.7 \%)$ & $1(2.2 \%)$ & $1(7.1 \%)$ \\
\hline IDDM & 0 & $3(6.7 \%)$ & 0 \\
\hline DMII & $1(3.8 \%)$ & & $3(21.4 \%)$ \\
\hline
\end{tabular}

NIDDM: Non-insulin Dependent Diabetes Mellitus; IDDM: Insulin Dependent Diabetes Mellitus; DMII: Diabetes Mellitus Type 2. Values expressed as means and percentage of the total. 
22.3/10, respectively. There was no statistically significant difference in the pre-operative mean hemodynamic measurements. The pre-operative mean plasma normetanephrine/metanephrine was 5.5/1.3 nmol/L in Group A, 9/4.8 nmol/L in Group B, and 27.4/8.4 nmol/L in Group C. There was a statistically significant difference when comparing normetanephrine/metanephrine levels, relative to tumor size. Specifically, when comparing group A to group $C$, group $B$ to $C$, but not group $A$ to $B$. Table 3 details the above findings. When considering hyper-adrenergic signs and symptoms (i.e. hypertension, headaches, palpitations, sweating, etc.), relative to size, there was only a statistically significant difference with respect to the presence of hypertension-but only when there was a larger discrepancy in size (i.e. $<4$ vs. $>8 \mathrm{~cm}$ ). Table 4 lists the clinical symptoms and associated co-morbidities relative to tumor size.

Mean blood pressures after anesthesia induction, within 30 minutes of procedure start time, and approximately 60 minutes from the procedure start time (i.e. when the adrenal vein is clamped) was measured and analyzed. Patients in Group $\mathrm{C}$ had more episodes of hypotension during surgery in comparison with the other two groups - but the most significant hypotensive episodes were after adrenal vein clamping. There was a statistically significant difference when comparing mean blood pressure at approximately 60 minutes from the procedure start time. Specifically, when comparing group A to group $C$, group $B$ to $C$, but not group $A$ to $B$. Otherwise, differences in mean blood pressures at the other peri-operative time intervals were not significant. Table 5 details the above findings.

\section{Discussion}

Laparoscopic surgery is the standard operative approach for the resection of benign pheochromocytomas. There is limited data determining absolute size cut-offs for laparoscopic adrenalectomies, and recent guidelines recommend a more individualized approach to this procedure [14]. This approach can be done via the transabdominal or retroperitoneal routes, depending on the size of tumor. The retroperitoneal approach is preferred for right adrenal pheochromo- cytomas [15]. When compared with open surgery, the laparoscopic method is associated with shorter hospital stays, improved cosmetic results, less blood loss, and decreased narcotic requirement. The previous thinking that peritoneal cavity insufflation with carbon dioxide results in paroxysmal hypertension has long been discarded [15]. Conversion of a laparoscopic case to an open one is usually done as result of difficult dissection due to adhesions, bleeding that is difficult to control laparoscopically, visualization of invasion (i.e. obvious gross signs of malignancy), and surgeon inexperience [9]. In our study 7 of the 73 laparoscopic cases were converted. In Group A, one case was converted to open technique in order to remove a right back mass - a lipoma. In Group $B$, there were three conversions to an open procedure as a result of bleeding and adhesions to surrounding organs (i.e. the kidney, the distal pancreas, and the splenic flexure of the colon). In Group C, there were three conversions due to the need for a radical adrenalectomy (tumor invasion into the renal artery and/or parenchyma was visualized intra-operatively). Open adrenalectomies are reserved for pre-operatively confirmed malignant lesions of the adrenal gland $[9,15]$. In our cohort, only 5 patients underwent an open procedure. In Group A, two open cases were done - one for obvious extension into the splenic parenchyma and another for a high index of suspicion for malignancy due to radiological signs. Group B had only one open case, secondary to extension into the ipsilateral renal parenchyma. The two open cases in Group C were both due to encasement of the inferior vena cava.

Our study revealed no correlation between PCC size and pre-operative hemodynamic instability. That is, regardless of tumor size, there was no significant difference between pre-operatively measured heart rate and blood pressure (before commencing pre-operative medical management). On the other hand, the mean number of patients with hypertension in Group $C$ was significantly different than the mean in Group A, but not with Group C. Meaning, in our cohort of patients - those with a PCC tumor size of $>8 \mathrm{~cm}$ were more likely to have hypertension than those with a tumor size $<4$ $\mathrm{cm}$. No other symptoms of catecholamine excess were sig-

Table 5: Blood pressure values during surgery.

\begin{tabular}{|c|c|c|c|c|c|c|c|}
\hline \multicolumn{2}{|l|}{ Blood pressure } & \multicolumn{2}{|c|}{$\begin{array}{l}\text { Group A } \\
(\mathrm{n}=26)[<4 \mathrm{~cm}]\end{array}$} & \multicolumn{2}{|c|}{$\begin{array}{l}\text { Group B } \\
(\mathrm{n}=39)[4-8 \mathrm{~cm}]\end{array}$} & \multicolumn{2}{|c|}{$\begin{array}{l}\text { Group C } \\
(\mathrm{n}=14)[>8 \mathrm{~cm}]\end{array}$} \\
\hline & & SBP & DBP & SBP & DPB & SBP & DPB \\
\hline \multirow[t]{3}{*}{ After anesthesia induction } & Range & $(90-170)$ & $(40-110)$ & $(65-170)$ & $(35-90)$ & $(100-155)$ & $(50-90)$ \\
\hline & Mean & 132 & 74 & 136.8 & 69.1 & 135.8 & 72.5 \\
\hline & SD & 26.4 & 19.4 & 27.5 & 13.6 & 20.6 & 19.9 \\
\hline \multirow{3}{*}{$\begin{array}{l}\text { Within } 30 \text { min of procedure } \\
\text { start time }\end{array}$} & Range & $(80-145)$ & $(45-80)$ & $(95-140)$ & $(50-100)$ & $(90-140)$ & $(60-90)$ \\
\hline & Mean & 119 & 66.5 & 113.6 & 68.2 & 106.7 & 65 \\
\hline & SD & 21.4 & 12.7 & 20 & 14.1 & 17.5 & 12.2 \\
\hline \multirow{3}{*}{$\begin{array}{l}\text { Within } 60 \text { min of procedure } \\
\text { start time } \\
\text { [Adrenal vein clamping] }\end{array}$} & Range & $(80-140)$ & $(45-90)$ & $(80-140)$ & $(40-80)$ & $(85-100)$ & $(40-80)$ \\
\hline & Mean & 118 & 68.5 & 112.3 & 63.8 & 90 & 56.7 \\
\hline & SD & 21.4 & 12.5 & 21.1 & 14.1 & 5.5 & 13.7 \\
\hline
\end{tabular}

SBP: Systolic Blood Pressure; DBP: Diastolic Blood Pressure; bpm: Beats Per Minute. 
Citation: Guevara D, Meknat A, Bellistri AT, Suh H, Levine AC, et al. (2020) Differences in Adrenal Size as they Relate to Pheochromocytomas. J Surgical Endocrinol 2(1):16-20

nificantly different between the three groups. The reason behind the presence or absence of hyper-adrenergic signs and symptoms is multi-factorial. There are differences in clinical, biochemical, and pathological phenotypes amongst patients with PCC [3]. Hence, why these tumors have a wide spectrum of biochemical activity, symptoms, and presentations. Larger pheochromocytomas, that is $>8 \mathrm{~cm}$, showed to have significantly greater normetanephrine/metanephrine levels than those seen with tumors less than eight centimeters. This was not unexpected since catecholamine secretion reflects cell differentiation $[1,15]$. Further strengthening this point is the fact that the mean tumor size in Group $C(>8 \mathrm{~cm})$ was 9.8 while the means for Group A and B were clinically significantly smaller at 2.5 and 5.6, respectively.

Hypotensive episodes can occur after tumor resection and require continuous vasopressor agents despite treatment with aggressive volume expansion [16-18]. In this study, high levels of plasma normetanephrines/metanephrines and larger tumor size were considered to be tumor-related risk factors for intraoperative hypotensive episodes. The most critical step to avoiding hemodynamic instability during an adrenalectomy is clamping of the adrenal vein, flowing into the inferior vena cava on the right and the left renal vein on the left. This is an attempt to decrease catecholamine release into systemic circulation during handling and manipulation of the diseased adrenal gland [15]. There have been studies showing that tumor size and concentration of urinary catecholamine metabolites are strong predictors of prolonged hypotension after adrenalectomy, requiring greater duration of post-operative catecholamine support [16]. These findings corroborated what our study revealed. Group C (i.e. patients with a tumor size $>8 \mathrm{~cm}$ ) had a clinically and statistically significant difference in mean blood pressure after 60 minutes into the operation (when the adrenal vein was clamped).

\section{Conclusion}

This investigation demonstrated that tumor size could have an influence on the degree of plasma noremetanephrine/metanephrine secretion, the presence of select hyper-adrenergic symptoms (i.e. hypertension), on prolonging post-operative hypotension, and subsequent duration of post-operative catecholamine support. Pheochromocytomas are highly variable in their presentation. Moreover, the potential surgical approach and post-operative course are determined by the tumor characteristics. Therefore, each patient's care needs to be individualized based on their presentation, tumor characteristics, and biochemical profile.

\section{References}

1. Sandi-Jo Galati, Meena Said (2015) The Mount Sinai clinical pathway for the management of pheochromocytoma. Endocrine Practice 21: 368-382.

2. Kannan S, Purysko A, Faiman C, et al. (2014) Biochemical and radiological relationship in patients with pheochromocytoma:
Lessons from a case control study. Clin Endocrinol (Oxf) 80: 790796.

3. Lu Y, Li P, Gan W, et al. (2016) Clinical and pathological characteristics of hypertensive and normotensive adrenal pheochromocytomas. Exp Clin Endocrinol Diabetes 124: 372-379.

4. Van der Zee PA, de Boer A (2014) Pheochromocytoma: a review on preoperative treatment with phenoxybenzamine or doxazosin. Neth J Med 72: 190-201.

5. Samuel Zuber, Vitaly Kantorovich, Karel Pacak (2011) Hypertension in Pheochromocytoma: Characteristics and Treatment. Endocrinol Metab Clin North Am 40: 295-311.

6. Reese W Randle, Courtney J Balentine, Susan C Pitt, et al. (2017) Selective versus non-selective alpha-blockade prior to laparoscopic adrenalectomy for pheochromocytoma. Ann Surg Oncol 24: 244-250.

7. Anju Sahdev (2017) Recommendations for the management of adrenal incidentalomas: What is pertinent for radiologists? $\mathrm{Br} J$ Radiol 90.

8. Kim DW, Yoon SK, Kim SH, et al. (2017) Assessment of clinical and radiologic differences between small and large adrenal pheochromocytomas. Clinical Imaging 43: 153-157.

9. Shen WT, Sturgeon C, Clark OH, et al. (2004) Should pheochromocytoma size influence surgical approach? A comparison of 90 malignant and 60 benign pheochromocytomas. Surgery 136: 1129-1137.

10. Junsoo Park, Cheryn Song, Park M, et al. (2011) Predictive characteristics of malignant pheochromocytoma. Korean J Urol 52: 241-246.

11. Barwick TD, Malhotra A, Webb JA, et al. (2005) Embryology of the adrenal glands and its relevance to diagnostic imaging. Clin Radiol 60: 953-959.

12. SM Wilhelm, RA Prinz, AM Barbu, et al. (2006) Analysis of large versus small pheochromocytomas: Operative approaches and patient outcomes. Surgery 140: 553-559.

13. Iñiguez-Ariza NM, Kohlenberg JD, Delivanis DA, et al. (2017) Clinical, biochemical, and radiological characteristics of a single-center retrospective cohort of 705 large adrenal tumors. Mayo Clin Proc Innov Qual Outcomes 2: 30-39.

14. Fassnacht M, Arlt W, Bancos I, et al. (2016) Management of adrenal incidentalomas: European Society of Endocrinology Clinical Practice Guideline in collaboration with the European Network for the Study of Adrenal Tumors. Eur J Endocrinol 175: G1-G34.

15. Filip Čtvrtlík, Pavel Koranda, Jan Schovánek, et al. (2018) Current diagnostic imaging of pheochromocytomas and implications for therapeutic strategy. Exp Ther Med 15: 3151-3160.

16. Namekawa T, Utsumi T, Kawamura K, et al. (2016) Clinical predictors of prolonged post-resection hypotension after laparoscopic adrenalectomy for pheochromocytoma. Surgery 159: 763-770.

17. Guerrero MA, Schreinemakers JM, Vriens MR, et al. (2009) Clinical spectrum of pheochromocytoma. Journal of the American College of Surgeons 209: 727-732.

18. M Lafont (2015) Per-operative hemodynamic instability in normotensive patients with incidentally discovered pheochromocytomas. Journal of Clinical Endocrinology \& Metabolism 100: 417-421. 